\title{
The Management of Invasive Fungal Infections: What to Consider in Empirical Treatment?
}

\author{
Fatih DEMIRKAN ${ }^{1}$, Guray SAYDAM ${ }^{2}$, Bilgin ARDA A $^{3}$ M. Ali OZCAN ${ }^{1}$ \\ ' Dokuz Eylul University Faculty of Medicine, Department of Hematology \\ ${ }^{2}$ Ege University Faculty of Medicine, Department of Hematology \\ ${ }^{3}$ Ege University Faculty of Medicine, Department of Infectious Diseases \\ and Clinical Microbiology, Izmir, TURKEY
}

\begin{abstract}
Invasive fungal infections (IFI) are a major cause of morbidity and mortality in immunocompromised patients. Candida and Aspergillus are the most common fungi that lead to IFI. While invasive Candida infections are most commonly seen in patients in intensive care units (ICUs) and very low birth weight infants, aspergillosis is most frequent in immunocompromised patients, especially in patients with hematological malignancies and in those undergoing hematopoietic stem cell transplantation (HSCT). Empirical treatment should be considered in all high-risk patients with hematological malignancies suspected of having IFIs.
\end{abstract}

Keywords: Invasive fungal infection, Empirical antifungal therapy

ÖZET

Invaziv Fungal Enfeksiyonların Yönetimi: Ampirik Tedavide Dikkate Alınması Gerekenler

İnvaziv fungal infeksiyonlar (IFI) immünkompromize hastalarda morbidite ve mortalitenin önemli bir nedenidir. Candida ve Aspergillus, IFl'ye en sık yol açan mantarlardır. Invaziv Kandida enfeksiyonları en sık yoğun bakım ünitesi (YBÜ) hastalarında ve çok düşük doğum ağırlıklı bebeklerde görülmekte iken, aspergilloz özellikle hematolojik malignansili hastalarda ve hematopoietik kök hücre nakli (HKHN) yapılanlarda olmak üzere en sık immünkompromize hastalarda görülmektedir. Ampirik tedavi IFi olduğu şüphelenilen hematolojik malignansili tüm yüksek riskli hastalarda düşünülmelidir.

Anahtar Kelimeler: İnvaziv fungal enfeksiyon, Empirik antifungal terapi 


\section{Epidemiological Facts in Invasive Fungal Infec- tions - What Has Changed?}

The prevalence of IFIs is not known, but population-based survey data indicate a prevalence of 12-17 per 100,000 population. ${ }^{1}$ The annual number of deaths in which an IFI was written on the death certificate increased from 1,557 to 6,534 -a $320 \%$ increase from 1980 through 1997 in the United States. ${ }^{2}$ Along with the increase in the number of IFIs, there is an alteration in the type of fungal infections. In a retrospective review of autopsy cases in Toho University, Japan, a total of 411 cases of IFIs were detected among 10,297 autopsies. The prevalence of candidiasis decreased from 3.6\% (1981-93) to $2.0 \%$ (1994-2006), while that of aspergillosis increased throughout the 52-year period and reached $2.0 \%$. $^{3}$ Additionally, similar to the development of antibiotic resistance, the use of broad-spectrum antifungal agents such as voriconazole has led to the emergence of IFI caused by the mucormycetes class of fungi. ${ }^{4}$ In a case-control study involving 14 leukemic and 13 HSCT patients, voriconazole prophylaxis was identified as an independent risk factor, increasing the risk for invasive mucormycosis by more than 10 -fold. ${ }^{2}$ Singh et al. ${ }^{5}$ performed a prospective, matched case-control study of 50 solid-organ transplant recipients and found that voriconazole and/or caspofungin use increased the risk of mucormycosis by 4.4 times.

In another single-center series of autopsy-proven patients with hematologic malignancies, the prevalence of invasive aspergillosis and mucormycosis rose from $16 \%$ to $19 \%$ and from $1 \%$ to $3 \%$ respectively, while the prevalence of invasive candidiasis fell from $13 \%$ to $8 \%$.from 1989 through to $2003 .{ }^{6}$ The shift toward more invasive mold infections is critical as the overall 1-year survival is lower in invasive aspergillosis compared to invasive candidiasis in both HSCT (25.4\% vs. $33.6 \%)$ and solid-organ transplant patients (59\% vs. $66 \%)^{7.8}$

Another trend observed is the increasing incidence of non-albicans Candida spp. Candida tropicalis, Candida parapsilosis, and Candida glabrata have been isolated much more frequently as causes of invasive candidiasis worldwide, although $\mathrm{C}$. albicans remains the most common. ${ }^{9}$

\section{Diagnostics}

Despite advances in serological, molecular and imaging modalities, early diagnosis of IFI remains problematic. This situation becomes more critical as IFIs are most commonly seen in immunocompromised patients.

Although traditional culture-based tests produce low outputs and long time delays, they are inexpensive and provide valuable material on which to perform drug-sensitivity testing, which has become increasingly important, due to changing patterns of resistance. Histological evaluation of tissue specimens for fungi can be done rapidly, however, tissue biopsy may be too invasive for most immunosuppressed patients and simple light microscopy may not be specific enough for identification of some fungal species.

Galactomannan, an important component of the cell wall of Aspergillus spp., is released during early stages of growth, allowing the tests for its presence to be fairly sensitive (71\%) and specific $(89 \%) .{ }^{10}$ It can be detected in serum and in bronchoalveolar lavage (BAL) fluid thus providing a surrogate marker for the diagnosis of invasive aspergillosis. Although the commercially available enzyme-linked immunosorbent assay (ELISA) kits demonstrate good specificity, they have a variable sensitivity ranging from $17 \%$ to $100 \%$, mainly depending on the cut-off value used to determine the positivity. ${ }^{11}$ Until recently, the manufacturers recommended a serum ratio of 1.5 . However, recent studies have used a cut-off ratio of $0.5-1.0$, and the US Food and Drug Administration (FDA) approved a value of 0.5 . This cut-off ratio greatly increases the sensitivity at some loss of specificity. Galactomannan (GM) is also not specific for aspergillosis and can cross react with other fungal species such as Fusarium. A positive or negative GM test, whilst useful for determining a diagnosis of aspergillosis, does not exlude a diagnosis of mucormycosis.

There are some considerations in using galactomannan testing in medium high-risk patients with hematological malignancies (Table 1). Causes for false-positivity, cross reactivity and low sensitivity in galactomannan test are of concern and are presented in Table 2. ${ }^{12}$ The most common reason reported for false-positive GM results is the concomitant 


Table 1. Use of galactomannan testing for monitoring in medium high-risk patients
Frequency
Two or three times weekly during high level immunosuppression
Criteria for positivity
Two consecutive serum specimens with GMl > 0.5, and the test should be repeated before beginning therapy for invasive asper-
gillosis
Considerations
Galactomannan contamination may cause false positivity
Cross-reactivity caused by similar cell wall galactomannan may cause false positivity
Numerous foods (pasta, rice, etc.) that contain galactomannan may cause false-positivity
Damage to the gut wall by cytotoxic therapy, irradiation, or graft-versus-host disease may cause false-positivity
Mold-active antifungal drugs may cause false-negativity: repeat the test before implementing therapy for invasive aspergillosis
False-positive or false-negative results may occur for other reasons: clinical correlation is mandatory
GMI: galactomannan index

use of piperacillin-tazobactam. The use of antimold prophylaxis is known to attenuate the value of the GM assay. There is also some cross-reactivity with penicillium and other endemic fungi, such as histoplasma and blastomyces. Factors including diet, ice-pops, infections or concomitant drugs may affect GM test results.

Recently it has been indicated that galactomannan testing is not influenced by prophylactic treatment because of lower quantity of galactomannan..$^{13}$

The recent development of molecular amplification methods, such as polymerase chain reaction (PCR) and nucleic acid sequence based amplification (NASBA) for the rapid diagnosis of infections holds promise for increasing the sensitivity and specificity further, but standardization issues of the assays remain unresolved. PCR testing is not included within the European Organisation for Research and Treatment of Cancer/Invasive Fungal Infections Cooperative Group and the National Institute of Allergy and Infectious Diseases Mycoses Study Group (EORTC/MSG) criteria. Antigen detection and PCR have also been performed on other specimens such as BAL fluid. Although more prone to contamination, the negative predictive value of the assay remains high and these specimens may have some diagnostic utility.
Other surrogate markers for invasive fungal infection include the detection of secondary metabolites, proteomic approaches and the use of novel immunolabelling approaches to positron emission tomography. ${ }^{14}$

Testing of beta-D-glucan (a major cell wall constituent characteristic of most fungi), although approved by some reports for detecting invasive candidiasis and other fungal infections (except mucormycosis), has not received widespread acceptance due to difficulties in performance techniques and lack of specificity. ${ }^{15}$

Computed tomography (CT) scans of the chest are widely used as diagnostic tools when dealing with pulmonary or hepatic IFI in immunocompromised patients. Fungal infections such as invasive aspergillosis present with nodules surrounded by haziness (halo sign) and may be associated with cavitatory lesions. Identifying these lesions early allows earlier initiation of appropriate antifungal therapy. Similarly, defects in the liver architecture noted on CT scanning of the abdomen provide an early sign of an invasive fungal infection involving the liver. Treatment with antifungal drugs based on these early CT findings has been associated with improved survival. Mortality from aspergillosis is $>70 \%$ if diagnosis is delayed. ${ }^{16}$ On the other hand, halo (Aspergillus) or reverse halo sign (mucormycosis) 


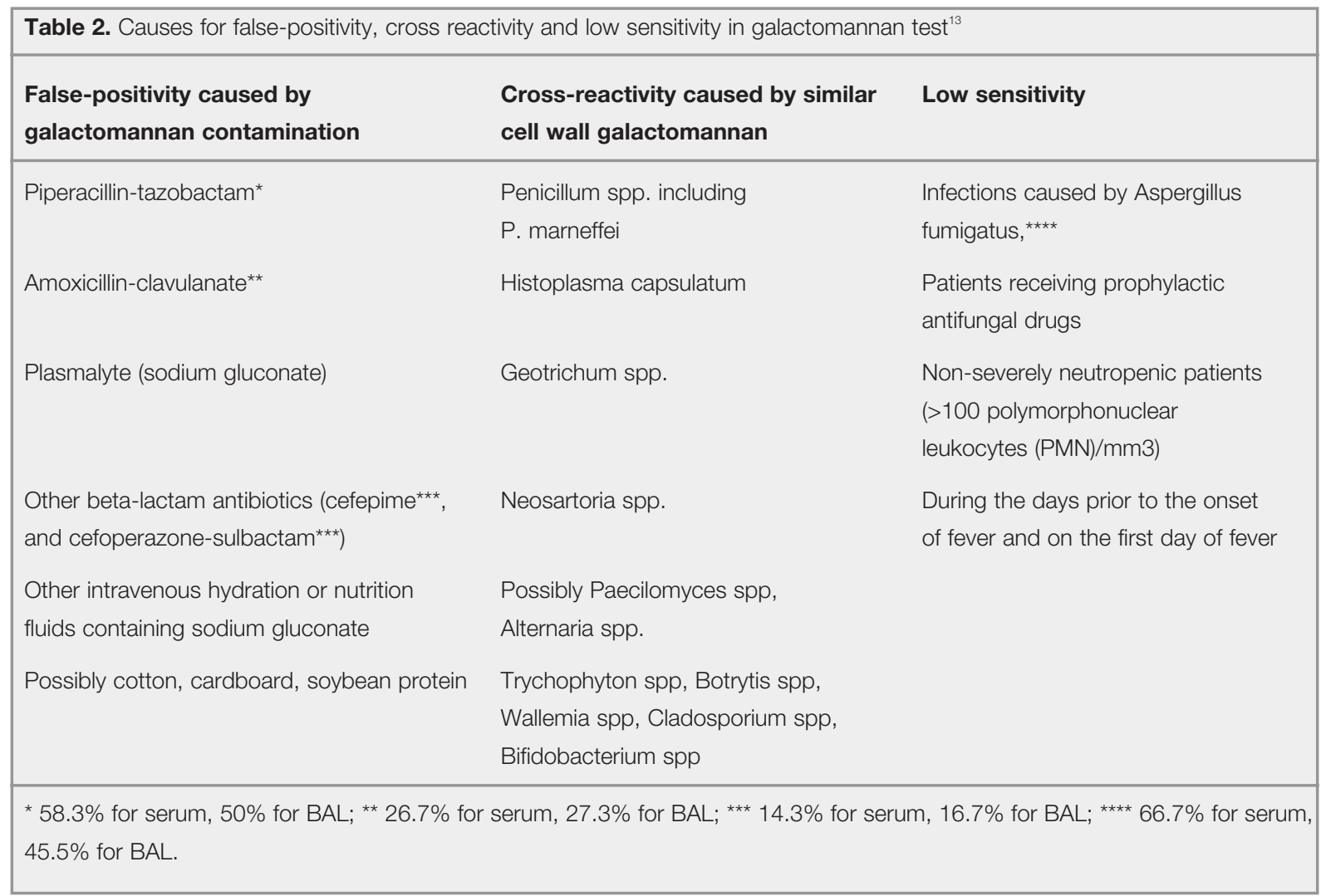

on chest $\mathrm{CT}$ are not pathognomonic and may be seen in a many infectious (bacterial, mycobacterial, viral or parasitic) and non-infectious (neoplasms, vasculitis, amyloidosis, etc.) diseases.

EORTC/MSG included antigen testing and radiology in the consensus definitions for diagnosing fungal infections. ${ }^{17}$

\section{Who is at Risk for Invasive Fungal Infections?}

The summary risk of an IFI depends on the overall net state of immunosuppression, especially, the intensity and duration of neutropenia and the epidemiologic exposures encountered. Patients can be classified into three main risk groups according to the degree of immunosuppression: ${ }^{18}$

a. High-risk: Patients with profound (absolute neutrophil count $<100 / \mathrm{mm}^{3}$ ) and prolonged ( $>14$ days) neutropenia or an important cell immunity deficiency resulting from chemotherapy, radiotherapy, cytomegalovirus (CMV) infection, graft-versus-host disease (GVHD) or treatment with corti- costeroids, anti-tumor necrosis factor (TNF)agents or alemtuzumab. Patients with allogeneic stem cell transplantation (SCT) with umbilical cord blood or allogeneic human leukocyte antigen (HLA)-mismatched SCT, allogeneic SCT with GVHD, and acute leukemias (myeloid or lymphocytic) and myelodysplastic syndromes during induction, re-induction or rescue therapy, are included in this group.

b. Medium-risk: Patients with neutropenia duration of 7- 14 days; HLA-matching allogeneic SCT and acute leukemias and myelodisplastic syndromes during consolidation or intensification chemotherapy are included in this group.

c. Low-risk: is characterized by neutropenia of $<7$ days as occurs frequently in autologous SCT.

The inclusion of a patient in one of the above-mentioned risk groups also depends on the other risk factors shown in Table 3. The assessment of each of these aspects can make us change the initial risk group defined according to criteria of Figure $1 .^{18}$ 


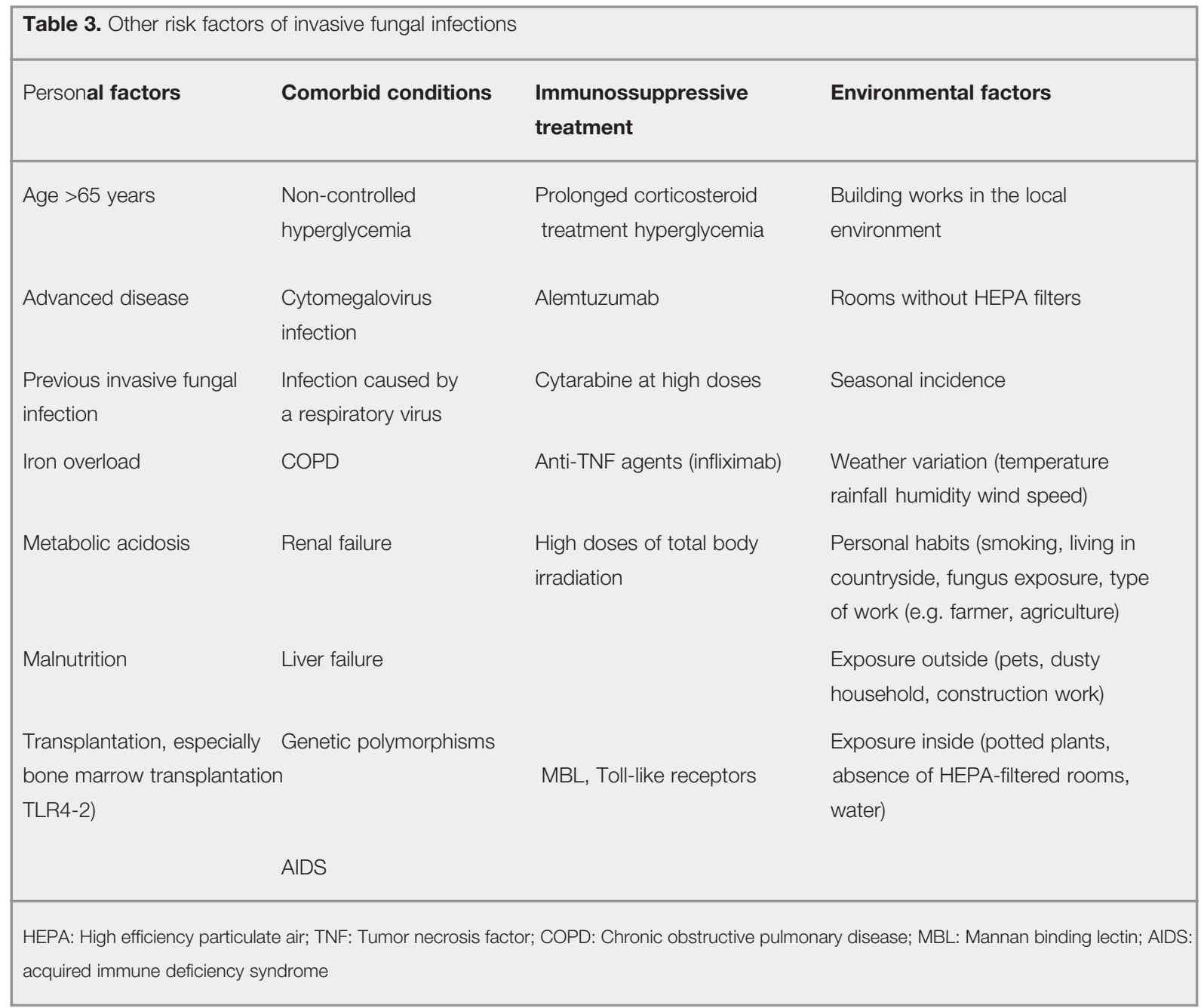

\section{Antifungal Treatment Strategies}

Antifungal drug usage can be divided into four strategies for prevention and treatment. These represent a continuum from prophylaxis (administration of drug to high-risk groups without evidence of disease), through empirical (administration of antifungals to neutropenic patients with persistent refractory fever) and pre-emptive, recently called the clinically driven diagnostic approach (using clinical, radiological and laboratory markers to determine the likelihood of disease), to treatment of established fungal infection. The differences between these strategies relate to 'time of commencing antifungal therapy and certainty of the diagnosis of IFI. The main aim of this paper was to discuss emprical treatment.

\section{Empirical Treatment: Pros and Cons}

Empirical treatment is defined as systemic antifungal treatment for a single oral temperature measurement of $\geq 38.3^{\circ} \mathrm{C}$ or a temperature of $\geq 38.0^{\circ} \mathrm{C}$ sustained over a 1 -h period despite broad-spectrum antibiotics (usually for 4-7 days) in the setting of neutropenia $\left(<0.5 \times 10^{9} / \mathrm{L}\right)$ in conditions where clinical, radiological and microbiological diagnostic evaluation has excluded other etiologies but has also failed to document a proven or probable IFI. ${ }^{19}$

Empirical treatment is given to medium- high-risk patients with fever that is unresponsive to $48-72 \mathrm{~h}$ of broad-spectrum antibiotic therapy, prior to diagnosis. As early diagnosis of IFIs is still challenging, early treatment remains an issue that needs to be addressed in many circumstances. Studies showed that early initiation of therapy seems to improve the 


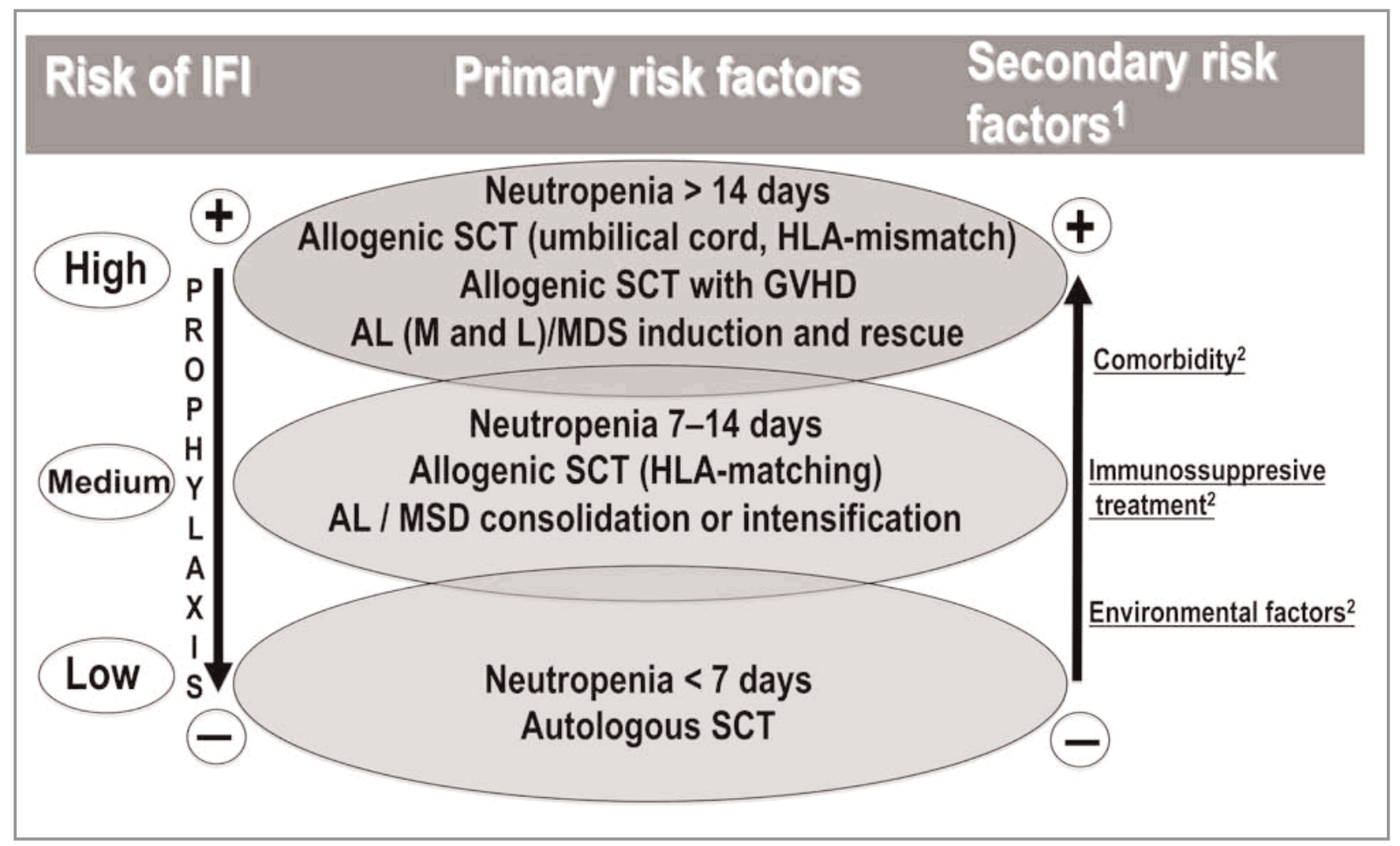

Figure 1. Risk factors of invasive fungal infections

${ }^{1}$ The presence of one or more of these factors may determine an increase of the risk group;

${ }^{2}$ See Table 3

IFI: Invasive fungal infections; SCT: stem cell transplantation; HLA: human leukocyte antigen; AL: acute leukemia; GVHD: graft-versus-host disease; M: myeloid; L: Iymphocytic; MDS: myelodysplastic syndromes.

Note: With kind permission from the Rev Esp Quimioter.

survival rate. Morrell et al. ${ }^{20}$ showed that administration of antifungal therapy after $12 \mathrm{~h}$ of having the first positive blood sample for culture drawn as an independent predictor of hospital mortality.

While making maximum use of available diagnostic tools, and trying to incorporate them into our clinical practice as standardized and valid tools, highrisk patients with hematological malignancies should be given empirical treatment.

The concept of empirical treatment in IFI emerged in 1980's with two studies conducted by the EORTC International Antimicrobial Therapy Cooperative Group ${ }^{21}$ and Pizzo et al. ${ }^{22}$ These two studies, which used amphotericin B deoxycholate (conventional amphotericin B) in treating IFIs, reported a decrease in the incidence and mortality of IFIs by this approach. However, dose limiting adverse effects of this compound led to studies with new compounds. Walsh et al., ${ }^{23}$ in their study in 1999, compared liposomal amphotericin B with conventional amphotericin B in the empirical treatment of IFIs. The authors demonstrated that liposomal amphotericin B had similar efficacy to conventional amphotericin B, but with fewer breakthrough fungal infections and a lower frequency of side effects, including infusion-related toxicity, and nephrotoxicity. The greater efficacy of liposomal amphotericin B was attributed to the fact that it was given at a dose of $3 \mathrm{mg}$ or more per kilogram with minimal dose-dependent toxicity.

Thereafter, in 2002 in a study comparing the efficacy of liposomal amphotericin B with a triazole, voriconazole, in the empirical treatment of IFIs, voriconazole did not meet the noninferiority criteria in treating IFIs in an empirical setting compared to liposomal amphotericin B. ${ }^{24}$ However, the authors stated that the overall response rate among patients 
who received voriconazole was similar to the rate among those who received liposomal amphotericin $\mathrm{B}$, and voriconazole was superior to liposomal amphotericin B in reducing breakthrough fungal infections, infusion-related toxicity, and nephrotoxicity. The FDA challenged the authors' conclusions in print and voriconazole is not approved for empiric therapy. ${ }^{25}$

Another study by Walsh et al ${ }^{26}$ investigated the efficacy and safety of caspofungin, an echinocandin, as compared to liposomal amphotericin B. The study was conducted in 1095 patients, 556 receiving caspofungin and 539 receiving liposomal amphotericin B. According to the results of the study, caspofungin was as effective as liposomal amphotericin B in the empirical treatment of IFIs. However, efficacy results of the study by Walsh et al. ${ }^{26}$ conducted in 2004 should be carefully evaluated. The patient group enrolled in the study was notably a lower risk patient population than the prior empirical studies with Allo-HSCT; the rate being $6.5 \%$ for the caspofungin group and $7.2 \%$ for the liposomal amphotericin B group. Whereas in the studies by Walsh et al. in 1999 (conventional amphotericin B vs. liposomal amphotericin B ${ }^{23}$ and in 2002 (voriconazole vs. liposomal amphotericin B) ${ }^{24}$ the allo-HSCT rates were $18.7 \%$ and $18.3 \%$, respectively. Also the rate of successful treatment of baseline fungal infection in patients using liposomal amphotericin B in the study by Walsh et al. ${ }^{26}$ conducted in 2004 was surprisingly lower (25.9\%) when compared to the prior empiric studies $(66.7 \%$ and $81 \%$ ). This may be due to the fact that in the study by Walsh et al. ${ }^{26}$ conducted in 2004 , the baseline fungal infections caused by rare molds other than Aspergillus flavus was higher in the liposomal amphotericin B group compared with the caspofungin group (In caspofungin group isolates included: Aspergillus candidus [two], A. flavus [two], A. fumigatus [five], and Aspergillus species not further identified [four]. The liposomal amphotericin B group isolates included A. flavus [five], A. fumigatus [one], A. niger [one], A. terreus [one], and Aspergillus species not further identified [five]). On the other hand, the preference to include successful treatment of any baseline fungal infection as one of the components of the primary endpoint may be also questionable since in the empiric setting the diagnosis of IFI is not confirmed.
Despite the fact that caspofungin is not recommended in the first-line treatment of invasive aspergillosis and rare molds, the rate of breakthrough infections have been found to be similar between caspofungin and liposomal amphotericin B in this study (5.2\% vs. $4.5 \%)$. Furthermore nephrotoxicity ( $2.6 \%$ vs. $11.5 \%)$, an infusion-related event $(35.1 \%$ vs. $51.6 \%)$, any drug-related adverse event $(54.4 \%$ vs. $69.3 \%$ ) or discontinuation of study therapy due to a drug-related adverse event (5\% vs. $8 \%$ ) was significantly lower in the caspofungin group vs. liposomal amphotericin B group.

In pursuit of trying to find a way to prevent drugrelated toxicity and costs related to over-treatment, the so-called preemptive treatment approach emerged with a study performed by Maertens et al ${ }^{27}$ in 2005. Maertens used galactomannan screening, HRCT and bronchoscopy to diagnose IFIs in highrisk neutropenic patients who had received fluconazole prophylaxis. Among the 41 febrile neutropenia episodes, 9 of them were treated preemptively; in addition, 10 episodes that were not suspected of IFI were treated by antifungal therapy. However, although diagnostic tests were used early in the treatment course, the study failed to identify 3 cases of IFI caused by non-Aspergillus species. The 12 -week survival rate was $63 \%$, and the authors stated that their findings in this pilot study should be investigated in further randomized controlled studies.

After the preemptive approach, with promising results, was introduced, studies comparing preemptive and empirical approaches were performed, with conflicting results. Cordonnier et al..$^{28}$ in their study in 2009 , comparing empirical treatment with preemptive approach analyzed the outcome of 293 hematological malignancy patients (150 in the empirical treatment arm and 143 in preemptive approach) with febrile neutropenia. Although they were able to show that preemptive treatment was non-inferior to empirical treatment in terms of survival in the analysis performed in all patients, the sub-group analysis of patients receiving induction chemotherapy showed that empirical approach was associated with a better survival outcome. Therefore, the authors suggested that empirical antifungal treatment may result in higher survival rates than would preemptive treatment among patients receiving induction chemotherapy. 
In 2010, Girmenia et al., ${ }^{29}$ used a clinically driven diagnostic approach in selected neutropenia episodes. At baseline, three blood cultures were performed. If the patient had 4 days of persisting or relapsing fever or other clinical findings possibly related to an IFI, an intensive diagnostic work-up (IDWU), including GM for 3 days, chest CT and other examinations were conducted. Overall, 49 IFIs were diagnosed during 48 episodes (21.8\%). Diagnostic driven therapy was administered to 48 patients with IFIs; one patient with zygomycosis died without treatment. Only one patient received empirical therapy. The authors stated that this approach provided effective antifungal control and reduced the exposure to unnecessary antifungal treatment. However, they stressed that non-Aspergillus infections may be a problem and in order to use this approach, the early availability of microbiologic and radiologic examinations is mandatory.

In 2011, Pagano et al..$^{30}$ analyzed the outcomes of empirical and preemptive approaches on 397 highrisk hematological malignancy patients in real life setting. Proven/probable IFIs were significantly lower in patients treated with empirical therapy (7.4\%) as compared to those treated preemptively (23.7\%). The invasive fungal disease-attributable death rate was significantly lower $(\mathrm{p}=0.002)$ in the empirical therapy group (1 case; $7.1 \%$ ) than that in the pre-emptive therapy group (11 cases; $22.5 \%$ ). The authors demonstrated that empirical therapy reduced the IFI-attributable mortality and increased survival probability of patients as compared to preemptive approach. The authors emphasized that the empirical approach is likely to guarantee a better outcome in hematological patients despite the risk of overtreatment, and empirical approach is probably the best treatment of choice when microbiological and radiological support is lacking. They also stated that pre-emptive therapy should be reserved for centers where a risk-based approach is feasible, using clinical rules and intensive diagnostic techniques to identify patients with IFI at a very early stage of disease. This study is the most important one in favour of empirical treatment against the pre-emptive approach, as it showed a survival benefit in those treated with empirical treatment.

Although empirical treatment is costly when compared to a pre-emptive approach, given the survival benefits mentioned in two studies, one in a real life setting and the other in a randomized controlled trial, empirical treatment should be started in highrisk febrile patients with hematological malignancies, who present with fever without an apparent focus for more than 3 days after a broad spectrum antibiotic treatment, while screening with available diagnostic tools are going on. As there are insufficient data supporting the pre-emptive approach, the European Conference on Infections in Leukaemia (ECIL)- 4 guideline has no recommendation for the pre-emptive approach. The grades of recommendation for empirical treatment are different in each of the guidelines published by different scientific societies. In the ECIL-3 guideline, the grade of recommendation is BII, in the Infectious Diseases Society of America (IDSA) AI for neutropenia lasting for more than 7 days, and AIII if the risk of IFI is low, and the Study Group for Infections in the Critically Ill Patient of the Spanish Society for Infectious Diseases and Clinical Microbiology SEIMC only recommends empirical therapy in patients with high or intermediate risk of aspergilosis and infections caused by other filamentous fungi. ${ }^{18}$

\section{Ideal Antifungal Treatment in Empirical Setting?}

An ideal empirical treatment should be effective against fungi most commonly seen in these patients, have a wide-spectrum of activity so that it can be effective in newly emerging species, and should have a favourable safety profile. The antifungal agents used in empirical treatment are polyenes, azoles and echinocandins, though some other antifungals, such as flucytosines are also available.

\section{Several factors should be considered in selecting an antifungal drug (Table 4). ${ }^{31}$}

Epidemiology of IFIs is an important factor in selecting the appropriate antifungal agent. Currently Aspergillus species are the most common fungi encountered in hematological patients, followed by Candida spp., and considering the changing resistance patterns and emergence of new fungi, the antifungal agent used should have a broad spectrum. Amphotericin B has a broad spectrum of fungicidal activity against Candida spp., Aspergillus spp., 


\begin{tabular}{|c|c|c|c|}
\hline \multirow{2}{*}{\begin{tabular}{|l} 
Epidemiology of invasive \\
fungal infection (IFI)
\end{tabular}} & \multicolumn{2}{|c|}{$\begin{array}{c}\text { Candida } \\
\text { Aspergillus } \\
\text { Other filamentous fungi }\end{array}$} & \multirow[b]{2}{*}{ Other filamentous fungi } \\
\hline & Candida & Aspergillus & \\
\hline Polyene & +++ & +++ & +++ \\
\hline Voriconazole & +++ & +++ & ++ \\
\hline Caspofungin & +++ & +++ & - \\
\hline Type of activity & Yeast & \multicolumn{2}{|c|}{ Filamentous fungi } \\
\hline Polyene & Fungicidal & \multicolumn{2}{|l|}{ Fungicidal } \\
\hline Voriconazole & Fungistatic & \multicolumn{2}{|l|}{ Fungicidal } \\
\hline Caspofungin & Fungicidal & \multicolumn{2}{|l|}{ Fungistatic } \\
\hline Clinical experience & $\begin{array}{l}\text { Efficacy against } \\
\text { Aspergillus }\end{array}$ & \multicolumn{2}{|c|}{ Evidence for breakthrough } \\
\hline Polyene & +++ & \multicolumn{2}{|l|}{-} \\
\hline Voriconazole & +++ & \multicolumn{2}{|l|}{+} \\
\hline Caspofungin & ++ & \multicolumn{2}{|l|}{+} \\
\hline Severity of infection & \multicolumn{3}{|c|}{ For empirical treatment select the antifungal agent with the highest efficacy } \\
\hline Prophylaxis with triazole or & In case of suspect & with liposomal & \\
\hline
\end{tabular}

Cryptococcus spp., Fusarium spp., Mucorales, and endemic fungi. Whereas, azoles have fungicidal activity only against Aspergillus spp., and echinocandins only against Candida. Voriconazole and liposomal amphotericin B have shown higher efficacy against Aspergillus infections in large randomised controlled trials ${ }^{32,33}$ whilst caspofungin has only a salvage indication in aspergillosis., Breakthrough Aspergillus and Mucorales infections have been documented during caspofungin and voriconazole treatment ${ }^{31,34}$ but not during amphotericin B treatment.

Polyenes are the oldest antifungal drugs, introduced in the 1950s, and lipid formulations of amphotericin B have less nephrotoxicity and infusion-related reactions as compared to conventional amphotericin $\mathrm{B}$, with liposomal amphotericin B showing the greatest reduction in infusion related adverse events and nephrotoxicity. As stated amphotericin B has a broad spectrum of fungicidal activity against common and emerging fungi, and has been used for over six decades with no documented acquired resistance.

Azoles, especially newer triazoles, have a broad spectrum of activity against fungal pathogens, and voriconazole is generally considered first line therapy for aspergillosis. However, drug toxicity, drug interactions, resistance to Candida and Aspergillus and emergence of the mucormycetes are of concern.

Echinocandins have a good safety profile and are highly effective against Candida infections; they are now recommended as the primary treatment option for candidiasis. However, they do not have ac- 


\begin{tabular}{|c|c|c|c|c|c|c|c|c|}
\hline & & & $\begin{array}{l}\text { Liposomal } \\
\text { amphotericin B }\end{array}$ & $\begin{array}{l}\text { Amphote- } \\
\text { ricin B }\end{array}$ & Caspofungin & Itraconazole & Voriconazole & Posaconazole \\
\hline \multirow{2}{*}{ 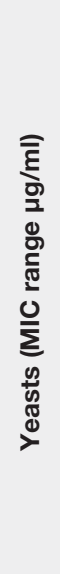 } & $\begin{array}{l}\frac{0}{0} \\
\frac{0}{0} \\
\frac{0}{00} \\
00 \\
\frac{\pi}{0} \\
\frac{0}{0} \\
\frac{E}{0} \\
0\end{array}$ & $\begin{array}{l}\text { C. albicans } \\
\text { C. glabrata } \\
\text { C. tropicalis } \\
\text { C. krusei } \\
\text { C. parapsilosis }\end{array}$ & $\begin{array}{l}0.015-0.12 \\
0.5-1.0 \\
0.25-1.0 \\
0.5-2.0 \\
0.5-1.0\end{array}$ & $\begin{array}{l}0.06-1.0 \\
0.125-2.0 \\
0.125-1.0 \\
0.25-2.0 \\
0.125-1.0\end{array}$ & $\begin{array}{l}0.06-0.25 \\
0.125-1.0 \\
0.125-1.0 \\
0.06-1.0 \\
0.5-2.0\end{array}$ & $\begin{array}{l}0.06-0.5 \\
0.5-4.0 \\
0.125-0.5 \\
0.5-4.0 \\
0.125-1.0\end{array}$ & $\begin{array}{l}0.06-0.25 \\
1.0-4.0 \\
0.06-0.5 \\
0.5-2.0 \\
0.06-0.5\end{array}$ & $\begin{array}{l}0.06-0.5 \\
0.5-4.0 \\
0.06-0.5 \\
0.5-2.0 \\
0.03-0.125\end{array}$ \\
\hline & 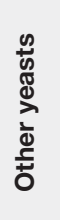 & $\begin{array}{l}\text { Saccharomyces } \\
\text { cerevisiae } \\
\text { Trichosporon inkin } \\
\text { Trichosporon asahii }\end{array}$ & $\begin{array}{l}0.03-0.06 \\
0.03-0.06 \\
0.01-0.03\end{array}$ & $\begin{array}{l}0.5-1.0 \\
0.5 \\
1.0-2.0\end{array}$ & $\begin{array}{l}1.0-2.0 \\
4.0-8.0 \\
4.0-8.0\end{array}$ & $\begin{array}{l}1.0-4.0 \\
0.03-0.5 \\
0.03-0.5\end{array}$ & $\begin{array}{l}0.125-0.5 \\
0.01-0.03 \\
0.03-0.06\end{array}$ & $\begin{array}{l}0.5-1.0 \\
0.25-0.5 \\
4.0-8.0\end{array}$ \\
\hline 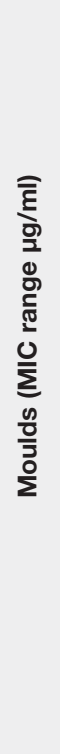 & 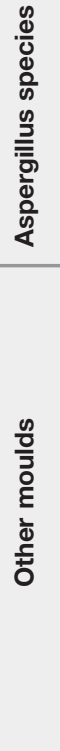 & $\begin{array}{l}\text { Fusarium oxysporum } \\
\text { Fusarium solani } \\
\text { Mucor spp. } \\
\text { Penicillium spp. } \\
\text { Rhizomucor spp. } \\
\text { Rhizopus spp. } \\
\text { Scedosporium } \\
\text { apiospermum }\end{array}$ & $\begin{array}{l}0.03-0.5 \\
4.0-8.0 \\
0.03-0.5 \\
0.5-1.0 \\
0.3-0.125 \\
1.0-4.0 \\
1.0-2.0\end{array}$ & $\begin{array}{l}1.0-4.0 \\
4 \\
0.5-1.0 \\
0.5-1.0 \\
0.25-1.0 \\
1.0-4.0 \\
2.0-4.0\end{array}$ & $\begin{array}{l}0.25-1.0^{\star} \\
0.125-1.0^{\star} \\
0.25-1.0^{\star} \\
0.25-1.0^{\star}\end{array}$ & $\begin{array}{l}1.0-8.0 \\
4.0-8.0 \\
4.0-8.0 \\
0.5-8.0 \\
\text { NA } \\
\text { NA } \\
2.0-4.0\end{array}$ & $\begin{array}{l}4.0->8.0 \\
\text { NA } \\
\text { NA } \\
2.0->8.0 \\
\text { NA } \\
\text { NA } \\
2.0->8.0\end{array}$ & $\begin{array}{l}0.125 \\
1 \\
2.0-4.0 \\
0.5 \\
1.0-4.0 \\
2.0-4.0 \\
0.5-2.0\end{array}$ \\
\hline $\begin{array}{l}{ }^{*} \mathrm{MEC} \\
\mathrm{NA}= \\
\text { Adap }\end{array}$ & $\begin{array}{l}\text { ange } \\
\text { lo Act } \\
\text { d fron }\end{array}$ & $\begin{array}{l}\text { /ml } \\
\text { ty (MIC or MEC range > } \\
\text { _ass_Flörl et al, } 2008\end{array}$ & $8 \mu \mathrm{g} / \mathrm{ml})$ & & & & & \\
\hline
\end{tabular}

tivity against non-Candida yeasts or against Cryptococcus, Fusarium and Scedosporium spp. or mucormycetes, and have fungistatic activity against Aspergillus spp., the most frequently encountered species in hematology patients.
Despite their potential toxicity, polyenes remain useful in the empiric treatment of IFIs because of their long track record, broad spectrum of activity and low rates of resistance. Furthermore, they are active against Mucorales. 
With prolonged use of antifungal drugs, particularly azoles and echinocandins, in prophylactic and empirical settings in immunocompromised individuals, clinicians should anticipate breakthrough infections. Whenever possible, accurate identification of the infecting organism is critical for the optimal management of breakthrough IFIs.

The antifungal spectrum of antifungal agents frequently used in clinical practice is given in Table $5{ }^{35}$

A diagnostic-oriented approach requires the availability of diagnostic tests with a rapid turnaround and the full cooperation and compliance of all parties involved, including clinicians, microbiologists, radiologists, nurses, or pharmacists, as well as a strict adherence to minimum standards of diagnosis.

In light of the literature and past experiences, we recommend empirical treatment in high-risk patients with hematological malignancies, bearing in mind that the patient should be meticulously examined and monitored to find the causative agent. The best antifungal therapy choice should consider both antimicrobial spectrum of the agent, and possible drug toxicities in order to tailor the treatment approach in these patients with multiple co-morbidities and concomitant drug usage.

\section{REFERENCES}

1. Lamagni TL, Evans BG, Shigematsu M, Johnson EM. Emerging trends in the epidemiology of invasive mycoses in England and Wales (1990-9). Epidemiol Infect 126: 397-414, 2001.

2. Low $\mathrm{CY}$, Rotstein $\mathrm{C}$. Emerging fungal infections in immunocompromised patients. F1000 Med Rep 3: 14, 2011.

3. Shimodaira K, Okubo Y, Nakayama H, et al. Trends in the prevalence of invasive fungal infections from an analysis of annual records of autopsy cases of Toho University. Mycoses 55: 435-443, 2012.

4. Skiada A, Pagano L, Groll A, et al. Zygomycosis in Europe: analysis of 230 cases accrued by the registry of the European Confederation of Medical Mycology (ECMM) Working Group on Zygomycosis between 2005 and 2007. Clin Microbiol Infect 17: 1859-1867, 2011.

5. Singh N, Aguado JM, Bonatti H, et al. Zygomycosis in solid organ transplant recipients: a prospective, matched case-control study to assess risks for disease and outcome. J Infect Dis 200: 1002-1011, 2009.
6. Chamilos G, Luna M, Lewis RE, et al. Invasive fungal infections in patients with hematologic malignancies in a tertiary care cancer center: an autopsy study over a 15-year period (1989-2003). Haematologica 91: 986989, 2006.

7. Kontoyiannis DP, Marr KA, Park BJ, et al. Prospective surveillance for invasive fungal infections in hematopoietic stem cell transplant recipients, 2001-2006: overview of the Transplant-Associated Infection Surveillance Network (TRANSNET) Database. Clin Infect Dis 50: 1091-1100, 2010.

8. Pappas PG, Alexander BD, Andes DR, et al. Invasive fungal infections among organ transplant recipients: results of the Transplant-Associated Infection Surveillance Network (TRANSNET). Clin Infect Dis 50: 11011111, 2010.

9. Pfaller MA, Diekema DJ. Epidemiology of invasive candidiasis: a persistent public health problem. Clin Microbiol Rev 20: 133-163, 2007.

10. Pfeiffer CD, Fine JP, Safdar N. Diagnosis of invasive aspergillosis using a galactomannan assay: a metaanalysis. Clin Infect Dis 42: 1417-1427, 2006.

11. Marr KA, Balajee SA, McLaughlin L, et al. Detection of galactomannan antigenemia by enzyme immunoassay for the diagnosis of invasive aspergillosis: variables that affect performance. J Infect Dis 190: 641-649, 2004.

12. Boonsarngsuk $\mathrm{V}$, Niyompattama A, Teosirimongkol $\mathrm{C}$, Sriwanichrak K. False-positive serum and bronchoalveolar lavage Aspergillus galactomannan assays caused by different antibiotics. Scand J Infect Dis 42: 461-468, 2010.

13. Maertens JA, Nucci M, Donnelly JP. The diagnostic role of galactomannan during antifungal prophylaxis. Comment on: "The role of antifungal treatment in hematology”. Haematologica 97: 325-327, 2012.

14. Barnes RA. Early diagnosis of fungal infection in immunocompromised patients. J Antimicrob Chemother 61 Suppl 1: i3-6, 2008.

15. Obayashi T, Negishi K, Suzuki T, Funata N. Reappraisal of the serum ( $\rightarrow 3$ )-B-D-glucan assay for the diagnosis of invasive fungal infections - a study based on autopsy cases from 6 years. Clin Infect Dis 46: 18641870, 2008.

16. von Eiff M, Roos N, Schulten R, et al. Pulmonary aspergillosis: early diagnosis improves survival. Respiration 62: 341-347, 1985.

17. Ascioglu S, Rex JH, Pauw B, et al. Defining opportunistic invasive fungal infections in immunocompromised patients with cancer and hematopoietic stem cell transplants: an international consensus. Clin Infect Dis 34: 7-14, 2002.

18. Barberán J, Mensa J, Llamas JC, et al. Recommendations for the treatment of invasive fungal infection caused by filamentous fungi in the hematological patient. Rev Esp Quimioter 24: 263-270, 2011. 
19. Turner SJ, Chen SC, Slavin MA, Kong DC. Pharmacoeconomics of empirical antifungal use in febrile neutropenic hematological malignancy and hematopoietic stem cell transplant patients. Expert Rev Pharmacoecon Outcomes Res 13: 227-235, 2013.

20. Morrell M, Fraser VJ, Kollef MH. Delaying the empiric treatment of candida bloodstream infection until positive blood culture results are obtained: a potential risk factor for hospital mortality. Antimicrob Agents Chemother 49: 3640-3645, 2005.

21. EORTC International Antimicrobial Therapy Cooperative Group. Empiric antifungal therapy in febrile granulocytopenic patients. Am J Med 86: 668-672, 1989.

22. Pizzo PA, Robichaud KJ, Gill FA, Witebsky FG. Empiric antibiotic and antifungal therapy for cancer patients with prolonged fever and granulocytopenia. Am J Med 72: 101-111, 1982.

23. Walsh TJ, Finberg RW, Arndt C, et al. Liposomal amphotericin $\mathrm{B}$ for empirical therapy in patients with persistent fever and neutropenia. N Engl J Med 340: 764771, 1999.

24. Walsh TJ, Pappas P, Winston DJ, et al. Voriconazole compared with liposomal amphotericin B for empirical antifungal therapy in patients with neutropenia and persistent fever. N Engl J Med 346: 225-234, 2002.

25. Petrikkos G, Skiada A. Recent advances in antifungal chemotherapy. Int J Antimicrob Agents 30: 108-117, 2007.

26. Walsh TJ, Teppler H, Donowitz GR, et al. Caspofungin versus liposomal amphotericin B for empirical antifungal therapy in patients with persistent fever and neutropenia. N Engl J Med 351: 1391-1402, 2004.

27. Maertens J, Theunissen K, Verhoef G, et al. Galactomannan and computed tomography-based preemptive antifungal therapy in neutropenic patients at high risk for invasive fungal infection: a prospective feasibility study. Clin Infect Dis 41: 1242-1250, 2005.

28. Cordonnier C, Pautas C, Maury S, et al. Empirical versus preemptive antifungal therapy for high-risk, febrile, neutropenic patients: a randomized, controlled trial. Clin Infect Dis 48: 1042-1051, 2009.

29. Girmenia C, Micozzi A, Gentile G, et al. Clinically driven diagnostic antifungal approach in neutropenic patients: a prospective feasibility study. J Clin Oncol 28: 667-674, 2010.

30. Pagano L, Caira M, Nosari A, et al. The use and efficacy of empirical versus pre-emptive therapy in the management of fungal infections: the HEMA e-Chart Project. Haematologica 96: 1366-1370, 2011.
31. Vallejo C, Barberán J. Empirical antifungal treatment: a valid alternative for invasive fungal infection. Rev Esp Quimioter 24: 117-122, 2011.

32. Herbrecht R, Denning DW, Patterson TF, et al. Voriconazole versus amphotericin B for primary therapy of invasive aspergillosis. N Engl J Med 347: 408-415, 2002.

33. Cornely OA, Maertens J, Bresnik M, et al. Liposomal amphotericin B as initial therapy for invasive mold infection: a randomized trial comparing a high-loading dose regimen with standard dosing (AmBiLoad trial). Clin Infect Dis 44: 1289-1297, 2007.

34. Chandrasekar P. Management of invasive fungal infections: a role for polyenes. J Antimicrob Chemother 66: 457-465, 2011.

35. Lass-Flörl C, Mayr A, Perkhofer S, et al. Activities of antifungal agents against yeasts and filamentous fungi: assessment according to the methodology of the European Committee on Antimicrobial Susceptibility Testing. Antimicrob. Agents Chemother 52: $3637-$ 3641, 2008.

\section{Correspondence}

Dr. Mehmet Ali ÖZCAN

Dokuz Eylül Üniversitesi Tıp Fakültesi Hastanesi

Hematoloji Anabilim Dalı

Mithatpaşa Cd

35340, İnciraltı, IZMIR / TURKEY

Tel: (+90.532) 3353721

Fax: (+90.232) 2599723

m-mail: mehmet.ozcan@deu.edu.tr 